\title{
ANALYSIS OF MOTIVATION, EXPECTATIONS ATTAINMENT AND SATISFACTION OF GRADUATE STUDENTS OF THE DEPARTMENT OF BIOCHEMISTRY, UNIVERSITY OF SÃO PAULO
}

\author{
Gabriel Santos Arini', Camila Aparecida Tolentino Cicuto ${ }^{1}$, Bayardo Baptista Torres ${ }^{1}$ \\ ${ }^{1}$ Universidade de São Paulo, Departamento de Bioquímica (São Paulo, Brasil) \\ Supported by: FAPESP and CNPq
}

INTRODUCTION: Aspects such as motivation, attainment of the expectations and satisfaction of students have been the target of studies aimed at improving teaching. Investigate the perception of graduate students and their experiences, as they progress in educational programs, provides data that can help improve these programs and support services. OBJECTIVES: This study aimed at analyzing the motivation, attainment of the expectations and satisfaction of graduate students in the Department of Biochemistry at the University of São Paulo regarding their own training as scientists and/or teachers. MATERIALS AND METHODS: Data were collected on October and November 2015, through the application of a questionnaire composed of three major categories: motivation, attainment of the expectations and satisfaction, and twelve subcategories: extrinsic, intrinsic and influenced by the environment motivation; attainment of expectations; satisfaction with the project; courses; scholarship; supervision; work environment; workload; deadlines; formation. The results were validated through Cronbach's Alpha (greater than 0,7$)$ and the item-total correlation index, larger than 0.2 in all items of the questionnaire. DISCUSSION AND RESULTS: Extrinsic motivation of students is strongly influenced by the perspective of progress in career (more than $65 \%)$. Intrinsic motivation is influenced by the aspiration to become scientists $(85.4 \%)$, learn more about their work $(94.3 \%)$ and contribute to the construction of Science $(83.1 \%)$. The motivation influenced by the environment affects these students for the high productivity of the program $(69.7 \%)$, the solid education it offers $(84.3 \%)$ and its reputation $(74.1 \%)$. The program has met the students' expectations $(72 \%)$; they are satisfied with their project $(77.6 \%)$, with the courses $(62.5 \%)$, and the supervision received $(76.4 \%)$, with the work environment $(83.2 \%$ intralaboratory; $64.1 \%$ extralaboratory), with the deadlines (over 61\%) and formation acquired $(71.6 \%$ ). Dissatisfaction focus on the value of the scholarship $(73 \%)$ and on their workload. CONCLUSION: The overall results show satisfaction with the graduate program in which they are enrolled and high intrinsic motivation for affiliation.

Keywords: intrinsic and extrinsic motivation; attainment of the expectations; satisfaction 